University of Rhode Island

DigitalCommons@URI

Open Access Master's Theses

1998

\title{
An Exploratory Study of Attachment Styles and Their Relationship to Emotional Intelligence in a Young Adult Population
}

Steven Kenneth Diehl

University of Rhode Island

Follow this and additional works at: https://digitalcommons.uri.edu/theses

\section{Recommended Citation}

Diehl, Steven Kenneth, "An Exploratory Study of Attachment Styles and Their Relationship to Emotional Intelligence in a Young Adult Population" (1998). Open Access Master's Theses. Paper 1622.

https://digitalcommons.uri.edu/theses/1622

This Thesis is brought to you for free and open access by DigitalCommons@URI. It has been accepted for inclusion in Open Access Master's Theses by an authorized administrator of DigitalCommons@URI. For more information, please contact digitalcommons-group@uri.edu. 


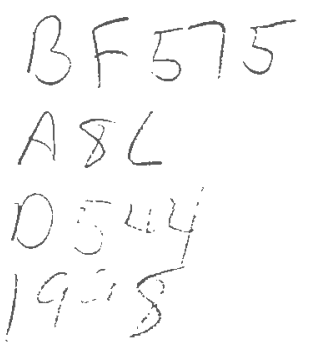

AN EXPLORATORY STUDY OF ATTACHMENT STYLES AND THEIR RELATIONSHIP TO EMOTIONAL INTELLIGENCE IN A YOUNG ADULT POPULATION

BY

STEVEN KENNETH DIEHL

A THESIS SUBMITTED IN PARTIAL FULFILLMENT OF THE REQUIREMENTS FOR THE DEGREE OF MASTERS OF ARTS

IN PSYCHOLOGY

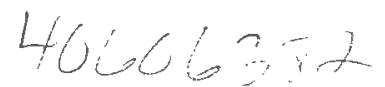

UNIVERSITY OF RHODE ISLAND 


\begin{abstract}
Since its inception, adult attachment theory has been used to identify individual differences within a wide range of interpersonal and intra-personal phenomena. Reviews of the literature suggest that securely attached adults are better able to cope with stressors and life demands both within themselves and in the context of significant social relationships than are adults exhibiting insecure styles of attachment. Research in the area of emotional intelligence suggests that people differ in their ability to utilize affective information to effectively cope with environmental demands and stressors. The present study examines the relationship between styles of attachment and individual differences in the abilities and skills that comprise emotional intelligence. Bartholomew and Horowitz's (1991) Relationship Questionnaire was used to assess attachment style and the BarOn Emotional Quotient Inventory (EQ-i) was used to measure emotional intelligence. Significant differences were produced in all six of the main analyses and on many of the exploratory comparisons. Overall, secure and dismissing adults performed equally well across most domains (with the exception of the interpersonal area) while the fearful subjects exhibited the lowest levels of emotional intelligence. Preoccupied subjects tended to fall between these extremes. The results tended to lend support to the twodimensional, four category attachment system devised by Bartholomew. Findings are related to previous research and are highlighted in terms of their possible contribution to developing appropriate intervention strategies for improving deficits in emotional skills and abilities.
\end{abstract}




\section{Acknowledgments}

I would like to mention the many people who have made the completion of this project possible. First, I would like to thank Henry Biller, my major professor, for his endless enthusiasm and helpful suggestions. His interest in making this study an extension of my true research interests is greatly appreciated and helped maintain the projects momentum and my inspiration.

I would also like to thank Peter Merenda, Gwenneth Rae, and Maria Garrido for their support, enthusiasm, and suggestions. Their insights into the study's design and implications are truly appreciated and made the project manageable and enjoyable. Through your input I grew from questioning student to questioning researcher.

I want to also thank Dana Gionta, a good friend and colleague. All I needed at times was someone to listen, and she was always there for me. Her support was invaluable.

Finally, I would be remiss if I did not thank my family and friends. If the following people weren't in my life in some way, this and any other degree would mean nothing to me. So a big thanks to Mom, Dad, Tim/Moon, Dani/Charlotte, Laura \& Brian B. (my faithful "assistants"), Derek, Carol, Dan H., Cecilia, Karyn, Keith, Kit, Amy, Doug, Brian G., Allison, Ryan, Yin, and everyone else that I don't have space to mention (you know who you are) for wondering when I was finally going to finish this thing. Thanks for being there - you guys are the best. 
Page

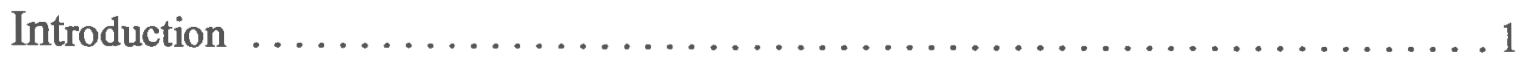

Attachment theory $\ldots \ldots \ldots \ldots \ldots \ldots \ldots \ldots \ldots \ldots \ldots \ldots \ldots \ldots \ldots \ldots \ldots \ldots$

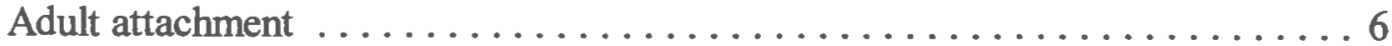

Emotional intelligence $\ldots \ldots \ldots \ldots \ldots \ldots \ldots \ldots \ldots \ldots \ldots \ldots \ldots \ldots \ldots \ldots$

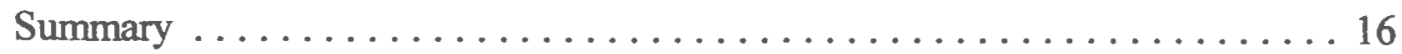

Research question and hypotheses $\ldots \ldots \ldots \ldots \ldots \ldots \ldots \ldots \ldots \ldots$

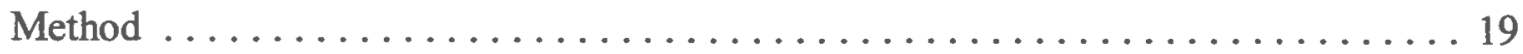

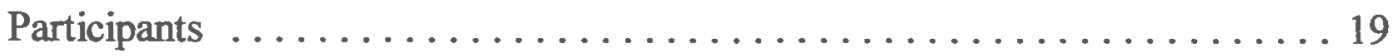

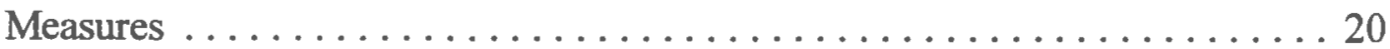

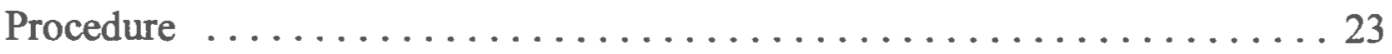

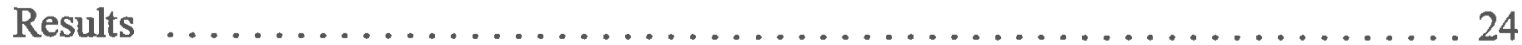

Test of specific hypotheses ...................... 24

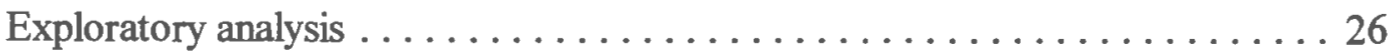

Discussion . . . . . . . . . . . . . . . . . . . . . . . . . . 30

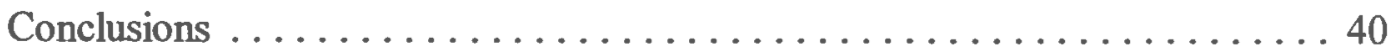

Possible Applications and Interventions . . . . . . . . . . . . . .42

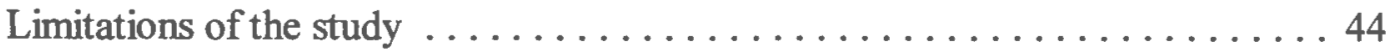

Summary and implications $\ldots \ldots \ldots \ldots \ldots \ldots \ldots \ldots \ldots \ldots \ldots$

Tables ........................................ 48

Appendix A Attachment measure......................... 50

Appendix B Demographic questionnaire $\ldots \ldots \ldots \ldots \ldots \ldots \ldots \ldots \ldots . .51$

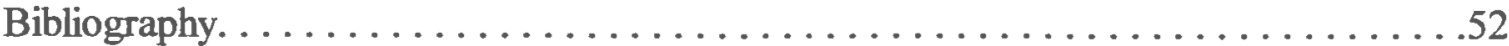




\section{List of Tables}

Page

1 Analysis of variance table for Total EQ and Composite ES scales . . . . . . . . . 48

2 Analysis of variance table for EQ content scales . . . . . . . . . . . . . . . 49 


\section{Introduction}

There is a substantial body of literature that suggests that adults who exhibit insecure patterns of attachment as compared to those who are securely attached have significant difficulties with affect regulation and forging successful relationships (Brennan \& Shaver, 1994, Hindy \& Schwarz, 1994, Berman, Marcus, \& Berman, 1994). One reason for this variation in relationship success and affect control may relate to individual differences among adults exhibiting the varying attachment styles and their ability to recognize, understand, and regulate emotions and other affective information. Recent research in the area of emotional intelligence by Bar-On (1997) and Salovey and Mayer (1990) may provide some insight into this possibility. These researchers believe that people differ in their ability to recognize and control their own emotions, as well as in their ability to understand and regulate the affective responses of other people. This study seeks to examine the possibility that the affective competencies and skills that comprise emotional intelligence are quantitatively different between subjects who exhibit a secure attachment pattern and subjects who exhibit insecure attachment patterns.

A review of the literature examines how attachment theory in its earliest formulations focused on individual differences among the quality of infant-mother dyad bonds. This extensive body of research has led more recent theorists to extend attachment theory's tenets to adult romantic relationships. Much of this research also focuses on individual differences between different "styles" of attachment. The research on emotional intelligence is discussed, with a particular emphasis on recent definitions and conceptualizations of this construct. Finally, the hypotheses of the present study are 
specifically outlined in an attempt to examine the relationship between styles of adult attachment relationships and individual differences in emotional and affective processing and regulation.

\section{Attachment theory}

Attachment theory in its earliest formulations sought to explain individual differences among infants in the way they relate to significant others (usually the mother) and regulate their inner distress during periods of separation from parents (Bowlby 1969, 1973, 1980). In Bowlby's influential three volume treatment of attachment theory, he sought to explain through evolutionary and ethological principles how a vulnerable infant increases its chances of survival through maintaining proximity to the primary caregiver. He postulates that proximity to caregiver is maintained because infants possess an evolutionary adaptive behavioral system which serves to activate certain behaviors when there is impending danger, the goal of which is to return to the secure base of the mother and father and gain a sense of felt security. The attachment system consists of a wide repertoire of behaviors such as crying, searching, cooing, crawling, and clinging to caregiver which serve to either signal the caregiver that the infant desires proximity or to maintain proximity to caregiver (Bowlby, 1973).

The attachment system as formulated by Bowlby includes a homeostatic function such that attachment behaviors are activated only in times of need. When no need exists and danger seems unlikely, the "set goal" of proximity is not violated and the infant is able to engage in other activities such as exploratory play. However, if the accessibility of the caregiver is in question (the proximity from caregiver has exceeded the "set goal"), the 
attachment system is activated and one of the behavioral responses is likely to be emitted by the infant. According to Bowlby (1982), this attachment system within the infant was separate and independent from other drive or behavioral systems such as exploration and feeding.

Drawing from and building upon Bowlby's (1969) theory, Mary Ainsworth and her colleagues began to do systematic observations and laboratory experimentation into the individual differences exhibited in the quality of the attachment relationship between infant and caregiver (Ainsworth, 1967, Ainsworth, Blehar, Waters, \& Wall, 1978). The quality of attachment within a particular infant-caregiver dyad is in large part determined by the history of the interaction within the dyad and the degree to which the infant has come to expect a sense of felt security when in close proximity to the parent. Ainsworth et al. assessed these individual differences in attachment through a laboratory procedure called the 'Strange Situation,' consisting of a number of episodes of contact, separation, and reunion with a primary caregiver and a stranger to the infant. The procedure is designed such that the child's behaviors are observed and recorded under increasing conditions of stress and separation anxiety.

Based upon observations from the Strange Situation, Ainsworth identified and described three distinct patterns of attachment; secure attachment, insecure-resistant attachment, and insecure-avoidant attachment. Most of the infants (approximately 65\%) were classified as securely attached in that they exhibited a pattern of behavior characterized by signs of distress during separation, seeking comfort and using the caregiver as a safe haven upon reunion, and using the caregiver as a secure base by 
engaging in exploratory play in the caregiver's presence. During subsequent visits to the homes of this group of infants, Ainsworth et al. found that the primary caregiver of these infants were generally sensitive to their signals for proximity and responsive toward their needs.

Infants classified in the other two categories were seen as being insecurely attached, and the infant-parent interactions seemed to be of a poorer quality than those in the secure group. The insecure-resistant infants (approximately $10 \%$ of the sample) intermingled proximity-seeking behaviors with overt anger and protest behaviors toward the caregiver upon reunion under conditions of duress. During home visits, the caregivers of these infants were observed to be quite inconsistent in their responsiveness their infants signals, sometimes being emotionally unavailable and sometimes being overly intrusive. The insecure-avoidant infants (approximately $25 \%$ of the sample) tended to avoid approaching the caregiver for support upon reunion as if during distress their caregivers were not sources of comfort for them. The primary caregivers of these infants seemed to be rejecting of their infants attempts at proximity during home observation visits.

Bowlby (1973) and other attachment theorists state that these first primary interactions with the mother lead to the infant internalizing mental representations of 'self' and of 'others' based upon the history of this dyadic relationship. As infants construct such models, they develop expectancies about the social and emotional sequelae of interacting with people in their environment. The behavior of secure, resistant, and avoidant infants within the Strange Situation was thought to be the observable manifestation of these inner representations of self and of others, or the behavioral manifestation of their 'internal 
working models' (Bretherton, Ridgeway, \& Cassidy, 1990, Grossmann \& Grossmann, 1991). These internal working models were not only guiding behavior in the laboratory, but also were thought to be the model from which all future relationships would be viewed. In other words, according to attachment theory, the relationship that characterizes a particular mother-infant dyad gives rise to a mental model of self and of others that influence attachment behaviors (support and proximity seeking as well as support giving) through childhood, adolescence and adulthood (Main, Kaplan, \& Cassidy, 1985).

The influence of early infant-caregiver relationships on later relationships has received some empirical support. Elicker, Englund, and Sroufe (1992), for example, found that infant attachment classification patterns were reliably related to self-confidence and social skills at ten years of age. Children who were classified as securely attached as infants were more likely to be self-confident and exhibit adequate social skills at age ten as compared to children who were classified as resistant or avoidant as infants.

Evidence exists that the attachment pattern an infant exhibits seems to have consequences for future relationships, and these consequences are thought to be the result of the internal working models forged during infancy via parent-child interactions (Benoit \& Parker, 1994). Other studies have found that security (or insecurity) of attachment in infancy is able to reliably predict a wide range of phenomena during the preschool and elementary school years, including school adjustment, behavioral problems, quality of relationships with peers and non-parental adults, and quality of familial relationships (Lewis, Feiring, McGuffog, \& Jaskir, 1984, Kenderville \& Main, 1981, Erickson, Sroufe, 
\& Egeland, 1985, Waters, Wippman, \& Sroufe, 1979, Sroufe, Egeland, \& Kreutzer, 1990).

\section{Adult attachment}

The idea that attachment relationships continue to be important after infancy and throughout the lifespan is a central tenet of attachment theory (Bowlby, 1988, Ainsworth, 1985, 1989). Expanding upon attachment theory, Hazan and Shaver (1987) extended its tenets to adult romantic relationships. They translated the components of attachment theory relating to the formation of affectional bonds between infant and caregiver to terms appropriate to adult romantic relationships. They sought to examine if romantic love is itself an attachment process. Based upon Ainsworth's three-category model of infant attachment, they developed a self-report instrument of adult attachment styles, which asks subjects to decide which pattern best describes their orientation toward romantic relationships.

Hazan and Shaver (1987) reported evidence supporting a similar mechanism for both parent-child and romantic love dyads. They found the frequency of the three attachment styles were distributed among adults in similar proportions to those in infants. The adults' internal working models of attachment were also related to their attachment style as determined by the self-report instrument. Caring, intimacy, understanding, and supportiveness were characteristic of the secure adults' romantic relationships. In contrast, avoidant adults' relationships were marred by fears of intimacy while resistant (or anxious) adults' relationships were filled with feelings of obsession, emotional instability, and strong physical attraction. These findings spawned numerous research 
projects on patterns of adult attachment and how they relate to relationship satisfaction. These studies generally replicated Hazan and Shaver's (1987) conclusion that more securely attached adults do have more satisfying interpersonal and romantic relationships than insecurely attached adults (see Hammond \& Fletcher, 1991, Collins \& Read, 1990, Kirkpatrick \& Davis, 1994, Feeney \& Noller, 1990, Simpson, 1990).

Bartholomew and Horowitz (1991) expanded upon Hazan and Shaver's (1987) three-category attachment typology based upon Bowlby's (1973) theory that one internalizes early attachment experiences via working models of self and of others. Bartholomew (1990) dichotomized the self and other variables to form a 2 × 2 matrix ('model of self by 'model of others) which provides prototypes for four attachment patterns. She proposes that one can have a positive or negative working model of self (self as worthy or love and support or self as not worthy of love and support) as well as a positive or negative working model of others (others viewed as accepting and trustworthy or others viewed as rejecting and untrustworthy).

The four prototypic patterns emerge when the model of self is considered in conjunction with the model of others. The secure pattern is characterized by positive views of oneself as being worthy of love and other people as being responsive and accepting (positive self/positive other). The preoccupied pattern, which corresponds to Hazan and Shaver's insecure resistant group, believe themselves to unworthy of love while relationships with other people are viewed as being highly valued (negative self/positive other). The fearful pattern, which is a sub-category of Hazan and Shaver's insecureavoidant group, is characterized by feelings of unworthiness and evaluations of others as 
non-responsive and rejecting (negative self/negative other). Finally, the dismissing pattern, which partially corresponds to Hazan and Shaver's avoidant classification, is characterized by feelings of self-worth, but distrust of others (positive self/negative other). A self-report instrument based on this four-category model of adult attachment was developed in which subjects are asked to decide which pattern best describes their orientation toward valued relationships (Bartholomew, 1991). Subsequent work has confirmed the construct validity of these self and other dimensions which are the basis of the four category model of attachment, as well as the attachment measure (Griffin \& Bartholomew, 1994) (see methodology section for further details).

Based upon the work of Hazan and Shaver (1987) and Bartholomew and Horowitz (1991), researchers have been studying the effects of individual differences in attachment classification as they relate to interpersonal experiences. Pistole (1995) found that upon the ending of significant love relationships, securely attached adults were more likely to report positive experiences upon the dissolution of the relationship while preoccupied and fearful adults reported more negative grief experiences. Sperling and Berman (1991) reported that those classified as being preoccupied described more feelings of desperate love and over dependence on their partner, as compared to securely attached adults.

Baldwin, Fehr, Keedian, Seidel, and Thomson (1993) found that securely attached adults have more positive expectations when interacting in a variety of interpersonal domains as compared to insecurely attached adults. In the second phase of their study, they discovered that secure subjects identified more positive outcomes in the interpersonal 
realm as compared to insecure subjects. Williams and Schill (1994) found that feelings of anxiety and fear of being abandoned and unloved in current romantic relationships correlated with an insecure attachment style with parents.

Internal working models related to specific attachment styles have also been found to be associated with certain intra-personal processes and personality characteristics. Preoccupied and dismissing adults are more hostile, more anxious, and less trusting of the social world (Kobak \& Sceery, 1988, Collins \& Read, 1990). Secure adults have been found to be less neurotic, more extraverted, and more agreeable than insecure subjects. Dismissing adults are less open to explore their feelings and fantasies while preoccupied adults are less open to explore their values and ideas as compared to secure adults (Shaver \& Brennan, 1992). Preoccupied adults have also been found to be high in dependency and overinvestment in other people, while dismissing adults tend to be self-centered and autonomous in day to day interactions (Zuroff \& Fitzpatrick, 1995).

The strategies that people use to deal with real-life stressors have also been found to vary by attachment pattern. Secure people cope with stress and trauma by acknowledging their feelings and turning to others for support. Preoccupied people, however, tend to report more distress, tend to be hyper vigilant of the distress, and tend to seek support in a clinging, dependent fashion that often increases their anxiety. Dismissing and fearful subjects tend to avoid social support, minimize emotional display, and somaticize their anxiety when stressed (Mikulincer \& Florian, 1995, Mikulincer, Florian, \& Weller, 1993, Mikulincer, Florian, \& Tolmacz, 1990).

In an especially provocative study, Brennan and Shaver (1995) examined 
attachment style differences as they relate to certain affect regulation strategies and specific unhealthy behaviors including non-intimate sexual behavior, eating disorders, and the use of alcohol. As compared to securely attached adults, avoidant subjects drink larger quantities of alcohol and use alcohol to reduce stress and anxiety, avoid intimacy within romantic relationships by fantasizing about sexual encounters with other people, and by engaging in brief sexual encounters which they consider to be meaningless. Preoccupied subjects, as compared to secure adults, also drank to reduce stress and anxiety, and also had a tendency to have symptoms of eating disorders such as binging under conditions of stress.

Attachment classification has also been found to exert a considerable influence on patterns of self-disclosure, support giving and seeking, and perceived levels of social support. Mikulincer and Nachson (1991) found that secure and preoccupied adults showed more of a tendency to self-disclose to real and hypothetical partners than dismissing and fearful adults, and that they disclosed more personal data and were more attracted to and felt better interacting with a partner who was high disclosing rather than low disclosing. Priel and Shamai (1995) found that securely attached subjects perceived themselves to have a more rich social support network than insecurely attached subjects, and that they gleaned more satisfaction from that network. Finally, Simpson, Rholes, and Nelligan (1992) found that when couples were placed in an anxiety provoking situation, those with a secure attachment style were more verbally supportive of their partners, were more likely to physically touch their partners, and were more likely to seek and give emotional support as compared to those with an insecure attachment style. 
Taken together, the adult attachment literature strongly suggests that ones adult attachment style has profound effects on a wide range of interpersonal and intra personal phenomena. While securely attached adults seem to be able to forge successful relationships, deal competently with adversity, and handle stress effectively, fearful, preoccupied, and dismissing adults have more difficulty in such areas. One reason for this may be that secure adults process emotional information more efficiently and effectively using their positive working models in everyday situations. The processing of emotional information is at the core of a recently resurgent research area, emotional intelligence.

\section{Emotional intelligence}

The renewed interest in emotional intelligence was in part spawned from research done in South Africa and Israel by Reuven Bar-On and in the United States by Peter Salovey and John Mayer. Though their research was developed and conceptualized independently from one another, both Bar-On and Salovey and Mayer theorized on similar content areas. How can emotional intelligence be defined? Bar-On (1996b) defines it as "an array of capabilities, competencies, and skills which influence one's ability to succeed in coping with environmental demands and which directly affect overall psychological well-being (p. 2)," while Salovey and Mayer (1995) define it as "the capacity to process emotional information accurately and efficiently, including that information relevant to the recognition, construction, and regulation of emotion in oneself and others (p. 197)."

Bar-On's research grew from his work as a clinical psychologist where he became interested in determining the factors that led some people to be more successful in their relationships and dealing with environmental stressors. In particular he was interested in 
examining why some people who are cognitively intelligent as measured by IQ scores have difficulties in life while others who are less intelligent according to IQ scores sometimes may be quite socially successful. This led him to searching for forms of intelligence that were independent from measures of cognitive intelligence, a search that came to focus on personal or emotional intelligence (Bar-On, 1992).

While Bar-On's research on individual differences on measures of IQ and its effects on life success led him to focus on personal and emotional intelligence, Mayer and Salovey (1993) began by examining Howard Gardner's (1993) "multiple intelligence". construct. At the heart of Gardner's multiple intelligence theory is the idea that in addition to the cognitively loaded constructs historically associated with intelligence, there are individual differences in the ability and capacity to process affective information, and once it has been processed, to adapt and regulate the emotional sequelae. According to Gardner, this affective information conveys knowledge about an individual's relationship to their environment (Morris, 1992; Schwarz, 1990) and is processed via different pathways than the strictly cognitive information usually presented in tests of intelligence (Zajonc, 1980). This emotional side of intelligence fits with what Gardner refers to as "personal" and "social" intelligence.

Drawing upon Gardner's seminal work, Salovey and Mayer (1990) viewed emotional intelligence "as the subset of social intelligence that involves the ability to monitor one's own and other's feelings and emotions, to discriminate among them and to use this information to guide one's thinking and actions (p. 187)." They theorize that life tasks are laden with affective information, that such information is processed (possibly via 
independent pathways from cognitive information), and that there are individual differences in one's abilities and skills to process and regulate this information (Mayer \& Salovey, 1995, Mayer \& Salovey, 1993). The abilities and skills needed in processing emotional information are distinct from the skills typically measured on traditional intelligence inventories which normally focus on the processing of linguistic, mathematical and visio-spatial information (Mayer \& Salovey, 1990).

Expanding upon Gardner's (1983) idea of personal intelligence, Salovey and Mayer (1990) conceptualize emotional intelligence as being comprised of skills and abilities in five basic domains. First, there are individual differences in appraising and expressing one's own emotions. For example, alexithymia refers to a condition where people have great difficulty appraising and verbally expressing their emotions (TenHouten, Hoppe, Bogen, \& Walter, 1985). This first domain is akin to knowing one's emotions and being able to monitor them so as to better understand what one is feeling at any particular time. Second, there are individual differences in the regulation of one's emotions. This second domain is akin to being able to manage one's emotions as they arise appropriately so that one is not a 'slave' to them For example, some people experiencing negative emotions evaluate them to be part of their personality and a typical experience for them beyond their control, while others may attribute their negative emotions and moods as just fleeting setbacks which are under their control (Mayer \& Gashke, 1988). . Third, there are individual differences in the way people utilize their emotions to solve problems. Being able to use one's mood effectively for flexible planning, creative thinking, redirecting attention to other things, and for motivating oneself for dealing with 
environmental demands is a sign of processing emotions effectively. This is akin to using ones emotions in reaching ones goals in life.

While the first three domains postulated by Salovey and Mayer (1990) consist of intra personal skills and abilities, the final two are interpersonal in their conceptualization. The fourth domain suggests that there are individual differences in appraising emotions expressed by others. For example, some people are better able 'read' the emotional context of non-verbal stimuli such as facial expressions than other people (Archer \& Archer, 1977, Mayer, DiPaulo, \& Salovey, 1990). Scales measuring empathy and social responsiveness have similarly shown that some subjects are better able to understand the feelings of other people than other subjects (Dymond, 1949, Mehrabian \& Epstein, 1972). This is akin to recognizing the verbal and non-verbal emotions expressed by others and being attuned to such social signals so as to make more appropriate responses to people. The final domain suggests that there are individual differences in the ability to regulate the affective reactions of other people. Some people are popular and well-liked by other people while others go largely unnoticed or are actively disliked by others. Research on impression management shows that some people make a more favorable imprint on people than others because of being more socially competent (Goffman, 1959). The skillful handling of emotions within relationships, including romantic relationships and close friendships, is a crucial part of emotional intelligence.

Bar-On's (1996-b) conceptualization of emotional intelligence is quite similar to that of Salovey and Mayer (1990). Based on his professional experience and an extensive review of the relevant literature, he identified via factor analytic studies fifteen components 
of emotional intelligence, which he groups into five basic clusters; (1) the intra-personal, (2) inter-personal, (3) cognition-orientation, (4) stress management, and (5) affect clusters. The intra-personal cluster is comprised of the emotional self-awareness, assertiveness, self-regard, self-actualization, and independence components identified from the factor analysis. The inter-personal cluster consists of the empathy, interpersonal relationship, and social responsibility components. The cognition-orientation cluster consists of the problem-solving skills, reality testing, and flexibility components. The stress management cluster is comprised of the stress tolerance and impulse control components. Finally, the affect cluster consists of the happiness and optimism factor analytic components (Bar-On, 1992).

Based upon his research findings, Bar-On (1996-a, 1996-c) developed an emotional intelligence measure, the BarOn Emotional Quotient Inventory (or EQ-i). The inventory gives an index of one's overall emotional intelligence (Total EQ), as well as scores on the five basic clusters and the fifteen content scores on which the Total EQ is based. The five basic clusters are referred to as sub-EQ scores (see methodology section for more detail).

It is important to note that unlike cognitive measures of intelligence where it has been traditionally assumed that the abilities and skills measured are fixed and difficult to change, emotional intelligence as conceptualized by Bar-On (1996-b) and Salovey and Mayer (1993) is viewed as being more fluid and changeable. According to Bar-On (1996-b), "not only does the EQ-i provide a 'snap-shot' of one's degree of emotional intelligence, but it can be used to identify areas for improvement and used to assess 
improvements over time (p. 12)." Goleman (1995), who calls the EQ-i a promising and pioneering effort in assessing key elements of emotional intelligence, emphasizes how we can improve basic emotional skills so that we can be better able to meet demands and succeed in life. To be emotionally intelligent suggests that one has developed the necessary abilities, competencies, and skills that allows one to process, manage, and regulate emotional stimuli and to meet environmental demands effectively and efficiently. When people exhibit difficulties in processing affective information, they may not be so successful in dealing with external and internal stresses and anxieties. Emotional intelligence theory (and the EQ-i in particular) can help identify those specific areas of need so that the necessary skills and competencies can be developed within the individual.

\section{Summary}

There is an extensive body of research which suggests that people who exhibit a secure, preoccupied, dismissing, or fearful adult attachment style have significantly different views of themselves and others in the context of adult romantic relationships. According to Bartholomew and Horowitz (1991), securely attached adults have internal working models in which they view themselves as being worthy of love and others as being responsive and accepting. Studies have shown that such adults typically have successful relationships with others and that they effectively regulate their emotional states within such relationships. Adults classified as having preoccupied, fearful, or dismissing attachment styles have internal working models in which they see either themselves as unworthy of love, others as being non-responsive, or manifest both a negative evaluation 
of self and other. In using these internal working models to guide their social interactions, insecurely attached (preoccupied, dismissing, and fearful) subjects manifest difficulties in the realms of interpersonal processes (such as relationship satisfaction), intra-personal processes (such as neuroticism and introversion), as well as stress management strategies (such as support seeking) when compared to adults having a secure attachment style.

Insecurely attached adults may have deficiencies in the abilities and skills which comprise emotional intelligence. For example, one key competency of emotional intelligence involves the ability to regulate one's inner distress. Research has shown that secure adults act in different ways under stressful conditions than do insecure adults. Another integral competency in emotional intelligence is the ability to empathize with the feelings of others. Adults exhibiting either a dismissing attachment pattern or a fearful attachment pattern view others through the lens of their internal working model as being untrustworthy and rejecting. Could these negative evaluations of others adversely affect their ability to feel empathy for these 'rejecting' and 'untrustworthy' outsiders? .

This study seeks to examine the possibility that securely attached adults will exhibit higher levels of emotional intelligence than adults exhibiting preoccupied, dismissing, and fearful patterns of attachment. Ascertaining the levels of emotional intelligence of adults exhibiting the four styles of attachment will help to pinpoint strengths and areas of need in their abilities to process and regulate affective information within themselves and in interactions with others. The hope would be that their internal working models of self and of others can be reorganized to improve their intra personal and interpersonal outlook upon life. 


\section{Research question and hypotheses}

Do adults who have a secure attachment style according to the Bartholomew and Horowitz (1991) classification typology exhibit better abilities at processing, regulating, and utilizing affective information according to the Emotional Quotient Inventory (EQ-i) than do adults who exhibit a preoccupied, fearful, or dismissing attachment style?

It is hypothesized that adult attachment classification is related to emotional intelligence as measured by the Total EQ score derived from the EQ-i. It is further hypothesized that the relationship is maintained on each of the five sub-EQ scores (the intra-personal, inter-personal, cognition-orientation, stress management, and affect domains). Emanating from these hypotheses are the following sets of predictions:

(1) Securely attached adults will attain a higher level of Total EQ than will adults who have insecure (preoccupied, fearful, dismissing) attachment styles,

(2) Securely attached subjects will attain higher levels on each of the five sub-EQ scores then will adults who have insecure attachment styles.

No predictions are made comparing differences among the three insecure attachment patterns. 


\section{Method}

\section{Participants}

Participants were 150 undergraduate students at the University of Rhode Island. The 114 females and 36 males were enrolled in an introductory psychology course and volunteered to participate in order to receive course credit. Of the 150 participants, 96 (64\%) were freshmen, 37 (24.7\%) were sophomores, 13 (8.7\%) were juniors, and 4 (2.7\%) were seniors. One hundred and twenty five (83.3\%) of the participants were White, 10 (6.7\%) were Asian, 5 (3.3\%) were Hispanic, 4 (2.7\%) were Black and 6 (4\%) indicated that they were biracial. The students' mean age was 18.77 years, and $78(52 \%)$ of the participants indicated that they were currently involved in a romantic relationship.

\section{$\underline{\text { Measures }}$}

Attachment Measure. Adult attachment style was determined using Bartholomew and Horowitz's (1991) single-item, self-report measure. The measure consists of four paragraphs which describe in a few sentences the thoughts and feelings associated with a secure, preoccupied, dismissing, and fearful attachment style. Examples from each of the paragraphs: (1) "It is relatively easy for me to become emotionally close to others" (from the secure prototype); (2) "I want to be completely emotionally intimate with others, but I often find that others are reluctant to get as close as I would like" (from the preoccupied prototype); (3) "I am uncomfortable getting close to others" (from the fearful prototype); and (4) "I am comfortable without close emotional relationships" (from the dismissing prototype). Subjects are asked to choose one of the four paragraphs that best describes 
their feelings about closeness and dependence within relationships (see the appendix for the complete paragraphs and directions).

Bartholomew and Horowitz's (1991) measure is an extension of the three category attachment instrument developed by Hazan and Shaver (1987). This procedure has been widely used in attachment research with results indicating good validity and reliability (Lyddon, Bradford, \& Nelson, 1993). A multi-item measure of the three category model was found to produce substantially the same results of those obtained using the single-item measure (Collins \& Read, 1990, Simpson, 1990, Mikulincer \& Arev, 1991), suggesting the use of the simpler instrument in attachment research.. The four category measure was developed to include the dismissing attachment style, which is characterized by positive feelings of self-worth combined with an expectation of others as being rejecting and untrustworthy. In a comparison of the three and four category measures, the same two dimensions (model of self and model of others) were found to underlie both instruments. Subjects had similar responses across both with only theoretically predicted differences between them (Shaver \& Hazan, 1993).

Data from the four-category measure yielded a configuration consistent with Bartholomew's (1990) two-dimensional model of attachment using a non-metric multidimensional analysis. Correlations among the four attachment styles were patterned as predicted by the model as well. For example, there was a negative correlation between the preoccupied and dismissing patterns (-.37), as well as between the secure and fearful patterns (-.65). Like the three category measure, the Bartholomew instrument has good face validity (Bradford \& Lyddon, 1994). Above and beyond the studies done on the 
three category measure, Griffin and Bartholomew (1994) did extensive research on the validity of the self and other dimensions which underlie the four category measure. The four category measure was significantly correlated to interview and friend report ratings of attachment, and all three measures independently produced similar patternings of the attachments styles, providing evidence of convergent validity (average coefficient of .38). Studies on the discriminant validity of the self and other models which underlie the measure suggest that these dimensions are independent from each other (average coefficient of .09). Finally, strong support was found for the construct and predictive validity of the attachment measure's self and other dimensions. For example, the positivity of an individual's reported self-model was highly correlated (.96) with the positivity of one's self-concept, while the positivity of an individual's reported other model was highly correlated (.93) to the positivity of one's interpersonal orientation (Griffin \& Bartholomew, 1994).

Emotional Intelligence Measure. The BarOn Emotional Quotient Inventory (EQ-i) (BarOn, 1996-a) was designed to assess an array of affective competencies, abilities, and skills which influence one's degree of success in coping with environmental demands and stressors. The measure consists of 133 statements which subjects are asked to rate on a five-point Likert scale on whether they are (1) Very Seldom or Never True of Me to (5) Very Often or Always True of Me. The measure takes approximately 30 to 40 minutes to complete. Factor analytic studies on which the EQ-i is based revealed 15 content scales. The content scales are then clustered into five sub-EQ scores: Intra-personal domain, 
Inter-personal domain, Cognition-Orientation, Stress Management, and Affect. Both the content and the sub-EQ's have a mean of 100 and a standard deviation of 15 . The results include a Total Emotional Quotient (Total EQ), also with a mean of 100 and a standard deviation of 15. According to Bar-On (1997), factor analytic studies firmly support the EQ-i's hierarchal structure. Completed answer sheets were sent out for computer scoring to Multi-Health Systems, based in Toronto, Canada.

According to Bar-On (1996-b, 1997), numerous research findings support the reliability and validity of the EQ-i. Reliability studies indicate that the internal consistency of items within each of the content scales are quite acceptable (Cronbach's alphas ranging from .70 to .89 ), and that the average test-retest reliability of the measure is .85 after one month, and .75 after four months. Studies examining the relationship between the EQ-i and different personality measures indicate that the measure has good construct validity. Studies examining EQ-i scores and their ability to differentiate between various successful and unsuccessful groups in terms of certain behaviors support the measure's discriminant validity. Other studies have indicated that the EQ-i has good criterion-group, convergent, and predictive validity as well (see Bar-On 1996-b, 1997).

Demographics. Subjects were asked to indicate their gender, race, age, year of study, and whether or not they were currently involved in a significant romantic relationship. Subjects were also asked to describe their satisfaction with this current relationship, or if they were not currently romantically involved, to describe factors they felt would be important to them within such relationships. 


\section{Procedure}

Sign-up sheets were used to recruit undergraduate students from an introductory psychology course to participate in the study. Participants were informed that they were being asked to take part in a study that examines the role that one's significant social relationships have on their experiences and perceptions of emotion in everyday life. After asking for questions and explaining and obtaining informed consent, participants were given a packet containing (1) the attachment questionnaire, (2) the BarOn EQ-i question booklet and answer sheet, and (3) the demographics form, in that order. Subjects were instructed to read the directions for measure and to complete them as indicated. Two trained researchers were available during each testing session to answer questions and address concerns of participants. The measures were administered in groups ranging from 8 to 40 participants per testing session. Participants were assured of the confidentiality of their responses, and were given a debriefing statement upon handing in the completed packet of measures. 


\section{$\underline{\text { Results }}$}

In preliminary analyses, $44 \%(66)$ of the 150 subjects endorsed the secure attachment style as describing them, $10.7 \%$ (16) endorsed the preoccupied style, $15.3 \%$ (23) endorsed the dismissing style, and $30 \%$ (45) endorsed the fearful style. The distribution of the attachment patterns is similar to those obtained by other researchers (Bartholomew \& Horowitz, 1991; Bylsma, Cozzarelli, \& Sumner, 1997). Chi-square analyses revealed no significant differences related to gender, race, year in college, or whether or not a subject was currently involved in a romantic relationship within the four category attachment classification system.

\section{Tests of Specific Hypotheses}

To evaluate the relationship between attachment style and emotional intelligence, six separate one-way analyses of variance (ANOVAs) were conducted. The primary hypothesis predicted that subjects who endorsed the secure attachment style would attain a higher level of Total EQ than would subjects who have insecure (preoccupied, fearful, dismissing) attachment styles. It was also predicted that securely attached subjects would also attain higher levels on each of the five EQ Composite Scale scores (the Intrapersonal, Interpersonal, Adaptability, Stress Management, and General Mood EQ Scales). Table 1 presents the mean Total EQ and EQ Composite Scale scores for each attachment style, along with the $F$-ratio and R Squared from each of the ANOVAs.

\section{Insert Table 1 about here}

The results in Table 1 indicate that there are differences among the attachment styles on the six EQ-i scales. The Tukey HSD test was used to evaluate pairwise 
differences among the means. Examining the differences on the Total EQ scale, which is a composite measure of general emotional competence, secure subjects had significantly higher scores than either preoccupied or fearful subjects. Dismissing subjects also had significantly higher scores than fearful subjects. This partially supports the primary hypothesis in that securely attached subjects only had higher scores than the preoccupied and fearful subjects, but not dismissing subjects.

In examining differences on the Intrapersonal Composite Scale, which is a general measure of one emotional intelligence as it relates to the inner self, both secure and dismissing subjects had significantly higher scores than preoccupied and fearful subjects. On both the Stress Management Composite Scale (which looks at general coping and impulse control abilities) and the General Mood Composite Scale (which examines general life outlook and attitude), the secure and dismissing subjects had significantly higher scores than fearful subjects. Again, these results only partially support the predictions in that secure subjects did not have higher scores than all three of the insecure styles on these particular EQ-i scales.

The one area in which secure subjects had uniquely high scores was on the Interpersonal Composite Scale, which is a general measure of interpersonal capacity. Here secure subjects had significantly higher scores than all three of the insecure groups. Finally, on the Adaptability Composite Scale, which is a general measure of adaptability in problem-solving, reality testing, and flexibility, secure subjects had significantly higher scores than fearful subjects while dismissing subjects had significantly higher scores than both the fearful and preoccupied subjects. 
Overall, the results indicate that secure subjects had higher scores than only the fearful subjects on all six of the main EQ-i scales. Unexpectedly, the dismissing subjects also had higher scores than fearful subjects on five of the six scales as well (the exception being the Interpersonal Composite Scale). Secure subjects also had higher scores than preoccupied subjects on three of the six scales (Total EQ, Intrapersonal, and Interpersonal Composite Scales), and only had higher scores than dismissing subjects on the Interpersonal Composite Scale.

\section{Exploratory Analysis}

The BarOn EQ-i also provides scores for $15 \mathrm{EQ}$ subscales which are components of the five EQ Composite Scales and the Total EQ scale discussed in the last section. Though no specific predictions were made in regard to the attachment styles on these subscales, 15 separate ANOVAs were conducted to further differentiate relative strengths and areas of need among the secure, preoccupied, fearful, and dismissing styles of attachment. Since all of these subscales are combined to create the Total EQ scale and certain of these subscales are used to create the Composite Scales already discussed, this analysis was also conducted to help further explain the pattern of results obtained in the last section. Table 2 presents the mean EQ Subscale scores for each of the attachment styles, along with the $F$-ratio and the R-Squared for each of the 15 ANOVAs.

\section{Insert Table 2 about here}

The results in Table 2 are divided such that the five EQ Subscales that comprise the Intrapersonal Composite Scale are grouped together, the three EQ Subscales that comprise the Interpersonal Composite Scale are grouped together, as are the subscales for 
the Stress Management, Adaptability, and General Mood composite scales. Using the Tukey HSD test to assess pairwise differences among the means, significant differences were found among the attachment styles in all five of the EQ Subscales from the intrapersonal domain.

Within the Self-Regard Subscale, (an individual's self-respect and selfacceptance), both secure and dismissing subjects had significantly higher scores than both preoccupied and fearful subjects. Within the Emotional Self-Awareness Subscale, (the ability to recognize and understand one's own emotions), secure subjects had significantly higher scores than both dismissing and fearful subjects, while preoccupied subjects had higher scores than fearful subjects. Within both the Assertiveness Subscale (the ability for one to express and defend their thoughts and feelings) and the Self-Actualization Subscale (the ability for one to reach one's potential), securely attached subjects had significantly higher scores than fearful subjects. Finally, on the Independence Subscale, (the ability to be self-directed and self-controlled in one's thinking and actions), secure, dismissing, and fearful subjects had significantly higher scores than preoccupied subjects.

Within the interpersonal domain, significant differences were found on all three of the relevant EQ subscales. On the Interpersonal Relationship Subscale, (the ability to establish and maintain satisfying relationships), securely attached subjects had significantly higher scores than both dismissing and fearful subjects. Within the Empathy Subscale, (the ability to understand and appreciate the feelings of others), secure subjects had higher scores than fearful subjects. Finally, on the Social Responsibility Subscale, (the capability to be a constructive and active member of social groups), despite the significant 
$F$-ratio reported in Table 2, no meaningful differences emerged via post hoc tests,.

Significant differences were found among the attachment styles on two of the three EQ Subscales from the adaptability domain. On the Reality Testing Subscale, (the ability to differentiate what is experienced from what objectively exists), both secure and dismissing subjects had significantly higher scores than the fearful subjects. Within the Flexibility Subscale, (the ability to adjust one's emotions, thoughts, and behavior to changing conditions), dismissing subjects had higher scores than both preoccupied and fearful subjects. The $F$-ratio for the Problem-Solving Subscale, (the ability to recognize, define, and solve problems), was not significant, though there was a tendency for both secure and dismissing subjects to have higher scores than both preoccupied and fearful subjects.

Within the stress management domain, there were significant differences on both of the relevant EQ subscales. On the Stress Tolerance Subscale, (the ability to cope with significant stressors), both secure and dismissing subjects had higher scores than fearful subjects. On the Impulse Control Subscale, (the ability to delay and/or resist temptation), secure subjects had significantly higher scores than fearful subjects.

Finally, significant differences were found among the attachment style groups on both of the subscales within the general mood domain. On the Happiness Subscale, (general life satisfaction and the ability to have fun in one's life), both secure and dismissing subjects had significantly higher scores than fearful subjects. On the Optimism Subscale, (the ability to have a positive outlook on life), both secure and dismissing subjects had higher scores than fearful subjects. 
The findings of this exploratory analysis are generally consistent with results obtained and described earlier in the tests of the study's specific hypotheses. Subjects with secure and dismissing attachment styles generally had comparable scores on the abilities examined by the EQ Subscales, and their scores tended to be higher than for those subjects who had fearful attachment styles. Finally, subjects with preoccupied attachment styles tended to have subscale scores between the secure/dismissing group and the fearful group. 


\section{$\underline{\text { Discussion }}$}

Based on attachment theory and research evidence, it was hypothesized that adults who exhibit a secure style of attachment would recognize, understand, and regulate emotion both within themselves and in others differently than adults with insecure styles of attachment. In particular, it was predicted that securely attached young adults would have quantitatively higher levels of emotional intelligence than insecurely attached young adults.

In general, the results of this study partially support the hypotheses. Looking at general emotional abilities first as measured by the Total EQ score, secure adults had better developed overall emotional abilities than both preoccupied and fearful adults. However, the secure and dismissing adults did not differ in overall emotional intelligence. Given that the Total EQ score only gives a general indication of emotional intelligence, the five Composite Scale scores were examined next to further interpret this pattern of results.

The Intra-personal Composite Scale is the component of emotional intelligence that pertains to an assessment of the inner self. High scores within this domain indicate individuals who feel good about themselves, who feel positive about what is happening in their lives, and who are independent and confident in their thoughts and feelings (Bar-On, 1997). On this scale, secure and dismissing adults had higher scores than both preoccupied and fearful adults. Again, it was predicted that the secure group would exhibit better developed abilities than all of the insecure groups. One reason that both the secures and dismissings may have scored higher in the intra personal realm is that both share a positive attachment self-model, while the preoccupieds and fearfuls share a 
negative self-model. Since both secure and dismissing adults view themselves in generally positive ways, it is not all that unexpected that they would both perform well in the intra personal domain. This interpretation of the influence of the positive self-model within the intra personal realm is further bolstered by a recent study where it was found that both secure and dismissing subjects had higher levels of self-esteem and self-perceived competence than preoccupied and fearful subjects (Bylsma, Cozzarelli, \& Sumner, 1997). Since both fearful and preoccupied adults have negative views of the self, it was expected that they would perform poorly in the intra personal realm.

The Interpersonal Composite Scale is that component of emotional intelligence that pertains to interpersonal functioning and capacity. High scores on this scale are indicative of people who are dependable and responsible, and who interact, understand, and relate well with others (Bar-On, 1997). As expected, secure adults had higher scores than all three insecure groups. This replicates past research which suggests that secure adults have more satisfying, balanced, and trusting relationships than adults exhibiting insecure attachment patterns (Kirkpatrick \& Davis, 1994; Hazan \& Shaver, 1987, 1994). People who exhibit a secure attachment style have a positive image of both the self as well as other people. In light of this attachment model, it is not surprising that they exhibited better developed skills and competencies in the interpersonal realm than did insecure subjects.

The Adaptability Composite Scale examines abilities relevant to coping with environmental demands and dealing with problematic situations. Here, secure adults were more effective, flexible, and realistic in handling difficult situations than the fearful adults 
alone, while dismissing adults had higher scores in this realms than both preoccupieds and fearfuls. Post hoc interpretation of this result is difficult in that the secure group $(M=95.36)$ did not differ from the preoccupied group $(M=85.75)$, while the secure group did significantly differ from the fearful group $(M=84.91)$, even though there is only a .84 mean difference between the fearful and preoccupied groups' scores in this domain. The general trend within the adaptability domain is for secure and dismissing subjects to have higher scores than both fearful and preoccupied subjects. Examined in this way, it would appear that adults who have a positive self-image and expectation of themselves (the secure and dismissing groups) tend to be better able to realistically and flexibly approach problems than adults who have a negative image and expectation of themselves (the fearful and preoccupied groups).

Bylsma et al. (1997) found that both secure and dismissing subjects judged themselves to be more competent than did fearful and preoccupied subjects in a variety of social, athletic, and romantic areas. It appears again that the positive image of self that the secure and dismissing groups have may translate into a basic self-confidence in their ability to gauge and solve problems. The negative self-models of the preoccupied and fearful groups, by the same token, may serve to lower their confidence in approaching problems, and may cause them to have difficulty reaching effective solutions.

The Stress Management Composite Scale is that component of emotional intelligence that relates to being able to withstand stress and to delay impulses. Both secure and dismissing adults had higher scores on this scale than did fearful subjects. There were no differences among adults exhibiting the secure, dismissing, or preoccupied 
styles of attachment. In fact the means of these three groups were within 3.5 points of each other while the fearful groups' scores were almost 10 points lower than those of preoccupied subjects. One reason that fearfuls may have such great difficulty in the area managing stress and resisting temptation is that while stressed, they lack the internal resources to effectively cope with demands and at the same time, they are unable to turn to others for assistance for fear of rejection.

According to Coe, Dalenberg, Aransky, and Reto (1995), fearful adults may suffer from such a sense of personal insecurity while stressed because they have negative images of both themselves and of other people. Under duress, they are unable to take refuge in preoccupation with other people (Preoccupied attachment) and they are unable to turn to themselves in the compulsively self-reliant way that dismissing adults do. In other words, because of personal distrust and avoidance (out of fear of rejection) of others, the fearful adults may feel as if they have nowhere to turn during times of stress. Dismissers may rely on themselves, preoccupieds may rely on others, and secures may look within themselves or to others under stressful conditions.

The positive-self internal working model seems also to have had an affect on the General Mood Composite Scale. In this area, which pertains to general life outlook and attitude and overall contentment, both secure and dismissing adults indicated that they are generally more positive, hopeful, and optimistic than fearful subjects. Together these two groups' means were also almost nine points higher than those of the preoccupieds, though this result did not reach statistical significance. It appears that having a positive self-model may lead one to view life in more hopeful and optimistic terms, while having a negative 
view of the self (like the fearful and preoccupied groups) may inhibit one from such positive views of life in general.

Pistole (1995) studied the emotional sequelae of relationship dissolution among college students and similarly found that upon ending a significant relationship, both secure and dismissing subjects reacted with less tension, confusion, and depression than preoccupied and fearful subjects. Fearful subjects tended to have the most negative outlook after the break-up while both secure and dismissing subjects had a much more positive outlook and reaction. Again, positive self-models seem to be where such results hinge in that negative or neutral events are interpreted more positively because those possessing such views of the self have the internal resources to overcome environmental stressors.

It was predicted that secure adults would have higher levels of the abilities and competencies that comprise emotional intelligence than all three groups of insecure subjects. However, it appears that with the exception of the interpersonal domain, dismissers are similar to secure adults in their levels of emotional intelligence. Throughout this pattern has been interpreted as an affect of the positive image of the self that both groups share. According to Bartholomew (1990), those exhibiting a dismissing style of attachment have learned to cope with unmet needs by "deactivating" the attachment system in general. "Over time, the strategies used to defend against the awareness of attachment needs become so engrained as to operate automatically...Individuals with this style passively avoid close relationships, they place much value on independence and assert that relationships are relatively unimportant. A focus on impersonal aspects of life, 
such as work or hobbies, is also expected (pp. 164-165)."

In other words, it appears that the high self-regard exhibited by dismissers is a function of a defensive deactivation of the attachment system and is at the expense of fulfilled intimacy needs. Therefore, these people may actually exhibit better stress management skills, problem-solving abilities, and higher self-esteem (which are likely to have been honed in the impersonal activities alluded to above), but they cut themselves off from the pleasures (and the feared pains) of involvement in intimate romantic relationships (as evidenced by their low interpersonal realm scores). Self-regard and self-esteem seem likely to result in successes in the realm of work and hobbies alone rather than from involvement in satisfying relationships. Overall, it seems that the dismissing group may recognize, understand, and regulate emotion within the self better than in the context of meaningful relationships. Whether this is the result of actual competency within these areas of emotional intelligence or if it is an artifact of defensive processes meant to protect the self from harm is unclear from this analysis.

While interpretation of the more general composite scales focused on the clear effects of the positive and negative self- and other-models of the four attachment styles, mean differences within the subscales (which pinpoint more specific strengths and areas of need) were less consistent. No specific predictions were made about subscale differences, and what differences arose are difficult, if not impossible, to interpret. For example, on the assertiveness subscale, fearful subjects $(M=91.51)$ had higher scores than preoccupied subjects $(M=91.44)$, yet secure subjects $(M=102.58)$ had significantly higher scores than only the fearful group. Extreme caution needs to be taken into account in interpreting 
this pattern of 'significance.'

Instead of embarking on such a tricky post hoc interpretation of mean differences between groups, it may be more fruitful to examine specific patterns that emerge within each of the four attachment patterns. Caution must be taken with this type of interpretation. Strengths on specific subscales are deemed by Bar-On (1997) as scores that fall one standard deviation above the mean (above 115) and weaknesses are indicated by scores one standard deviation below the mean (below 85). In no case were there any true 'strengths' by this definition, and only three true 'weaknesses' were identified (two within the fearful group and one within the preoccupied group). The individual variability of the mean subscale scores may obscure differences within the attachment styles, but this method of interpretation has the potential to highlight relative patterns of strengths and areas of need. This may provide useful information for future clinical and applied interventions.

Much of recent research on attachment theory has focused on bridging the gap between the theory's developmental foundations and clinical application and explanation (see Jones, 1996; Main, 1996; del Carmen \& Huffman, 1996). Hence, relative strengths and weaknesses will be identified within each style of attachment. I will highlight several of the highest and lowest subscale scores within each attachment style, with the caveat that the range between the highest and lowest subscales vary widely between the attachment groups (see Table 2).

Within the secure group, the highest scores were obtained on the interpersonal relationship, empathy, happiness, and emotional self-awareness subscales. This suggests 
that secure adults relate well to others, that they recognize and appreciate their own as well as others feelings, and that they are generally satisfied with their lives. They scored the lowest on the flexibility, problem-solving, and optimism subscales, though these scores were well within average ranges of competency as defined by Bar-On (1997). These scales relate to life outlook as well as general success in coping with environmental demands. The range between the lowest subscale (flexibility) and the highest subscale (interpersonal relationship) is less than ten points and all scores are well within one standard deviation from the mean, suggesting that there is no one obvious strength or weakness within the secure group.

The highest scores within the preoccupied group were obtained on the emotional self-awareness, interpersonal relationship, and empathy subscales. This suggests that the preoccupied group understands the feelings of and relate well to others and that they are in touch with their own feelings. The focus of this group is very much on emotion, especially it appears in the context of important relationships, since within such relationships preoccupieds validate their self-worth. Not surprisingly, this group scored lowest on the independence, flexibility, and self-regard subscales. All three of these areas are close to being one standard deviation below the mean, suggesting they are definite weaknesses for preoccupied adults. In fact, the lowest mean score across all attachment groups was the preoccupieds' score for independence $(M=82.31)$. This serves to underscore the dependency on others that has been found to be characteristic of this group (Bartholomew \& Horowitz, 1991; Feeney \& Noller, 1990).

Preoccupied attachment has been associated with low levels of self-esteem in 
previous research as is evident in their deficits in the self-regard component. Also, it has been noted that preoccupied subjects often exhibit difficulty coping with uncertain, stressful conditions (Simpson et al, 1992; Mikulincer et al., 1993). For the preoccupied group, the range between the highest and lowest subscale scores is over 20 points, the largest differential among the attachment styles. This discrepancy suggests that the identified weaknesses may be points of interest for those involved in designing clinical interventions for adults with a preoccupied attachment style.

For the dismissing group, the highest scores were obtained on the independence, flexibility, and self-regard subscales. This suggests that dismissing adults generally have good self-acceptance and self-respect, that they tend to be self-directed in their actions, and that they can adjust effectively to changing environmental conditions. This replicates other researchers views of dismissers as valuing independence and autonomy (Bartholomew, 1990). Their lowest scores were obtained on the interpersonal orientation, emotional self-awareness, and assertiveness subscales. Again, two of these scales relate to understanding emotion within the self and within relationships.

The 'deactivated' attachment system postulated by Bowlby (1980) and Bartholomew (1990) for dismissive adults would suggest that these people defend against attachment related emotions both within the self and within the context of relationships. Emotions appear to go unappreciated and unrecognized by this group. One reason that they may have performed poorly on the assertiveness scale is that dismissers have difficulty explaining and expressing emotions to others. Research has shown that retrospective accounts of past relationships by dismissive adults has lacked clarity and 
detail (Bartholomew \& Horowitz, 1991; Main et al., 1985). Clinical interventions with this group may benefit from a focus on the understanding and expression of emotion, particularly within social relationships. The overall range between the highest and lowest subscale scores for this group was a little more than ten points, suggesting that most scales fall within average ranges of competency (see Table 2).

The fearful group, which generally had the lowest scores across all domains, scored highest on the empathy and independence subscales. It is doubtful if these could be labeled as strengths per se in that their highest scores were similar to those of the lowest subscale scores of the secure and dismissing groups. Where the fearful group performed the worst was on the optimism, reality testing, and impulse control subscales. They also did poorly in the self-regard, emotional self-awareness, and stress tolerance domains. Many of these scores were below or close to being below one standard deviation from the mean, suggesting they are true weaknesses with respect to emotional intelligence (BarOn,1997). This range of deficits points to numerous difficulties associated with having a negative internal working model of both the self and of other people. Previous research has shown that fearful subjects are introverted, exploitable, and lack assertiveness (Horowitz, 1996), have a tendency to 'fall apart' under stress (Coe et al.,1995), and generally have poor self-esteem and self-perceived competency (Bylsma et al., 1997). There are numerous points which could be addressed via therapeutic intervention for fearfuls, but it seems that it may be most beneficial to start with areas relevant to bolstering views of the self. In light of the relatively high levels of emotional intelligence displayed by dismissing adults (who have positive views of the self), it would seem wise to 
focus on views of the self first. Later interventions could build upon these gains and extend them to working on the understanding and regulation of emotion within relationships.

\section{Conclusions}

The results of this study suggest that taking into account perceptions of the self and others for those with particular attachment styles is integral in understanding the relative strengths and weaknesses with regard to emotional intelligence. Across all domains, the secure group (who possess both a positive view of self and of others) performed the best, while the fearful group (with a negative view of self and of others) performed the worst.

Interestingly, the dismissing group performed almost as well as the secure group except within the interpersonal realm. This group, with its emphasis on almost compulsive self-reliance (at the expense of valuing and enjoying relationships), seem to exhibit generally well-developed skills of emotional intelligence. Whether this is actually the case or is the result of defensive processes aimed at protecting self-image is unclear from this analysis.

The preoccupied group, who have a negative image of the self and a positive orientation toward others, seem to function at a level between the secure/dismissing groups and the fearful group. This group seems to excel in the areas of empathy and interpersonal relationships, possibly because much of their self-worth is validated through exchanges with valued others.

These results seem to support Bartholomew's two-dimensional, four category 
model of attachment as it applies to a young adult population. First, the proportions of the four attachment patterns are quite similar to those found in past research using the Bartholomew typology (see Bylsma et al., 1997; Bartholomew \& Horowitz, 1991). The similarity of these proportions across studies suggests some very preliminary evidence that the subjects' choice of a descriptive attachment pattern is non-random in nature.

Additionally, the patterns of scores obtained on the BarOn EQ-i profiles seem to be explained quite robustly based on the model of self and model of other which underlie Bartholomew's system. For example, the secure and dismissing groups, both with a positive model of the self, had significantly higher scores on the Intra-personal Composite scale, which focuses on independence, assertiveness, self-regard, and general overall views of the self. Hence, a positive self attachment model seems to correlate meaningfully with positive ratings of the self according to the BarOn EQ-i. Fearful and preoccupied subjects both with a negative models of the self, had significantly lower scores on this scale, as the Bartholomew model would suggest.

When examining scores on the Interpersonal Composite scale, it again appears that the model of self and model of other which are the basis of the four-category model provide explanatory power relating to relationship functioning. The secure group, with a positive self and other model, had significantly higher scores on this measure of interpersonal functioning and empathetic understanding than all three of the insecure groups. Again, each of these insecure patterns has one or more negative models of either self or of other which previous research has suggested has adverse effects within the context of interpersonal relationships. Similarly, the pattern of results on the Stress 
Management, Adaptability, and General Mood Composite scales, as discussed earlier, are all consistent with research findings based upon the Bartholomew model.

These results also seem to indicate that attachment patterns explain processes beyond those involved in interpersonal relationships. For example, the positive self-model of the secure and dismissing subjects led them to view themselves, independent of significant relationships, in more positive terms. Indeed, individual differences across attachment groups also seems to have an affect on problem-solving strategies, the ability to manage stress, and general life outlook. Attachment theory was conceived to explain interpersonal phenomena, but it clearly seems to describe both intra- and extra personal processes as well. Researchers within the field of should continue to explore these intersections between patterns of attachment and areas outside the realm of relationship processes. Such research will extend the breadth of attachment theory while simultaneously suggesting fruitful practical applications.

Overall, then, the results confirm expectations generated directly from and support the validity of Bartholomew's four category attachment system. Specifically, Bar-On's theory of emotional intelligence seems to relate in a meaningful way to distinct patterns of adult attachment in that most of the results from the EQ-i can be interpreted in light of the valence of the self and the other model of attachment. This suggests some preliminary evidence of the validity of the BarOn EQ-i as well. However, because of the unavailability of the validity data and factorial components of the EQ-i at this time, these results are exploratory in nature and need to be re-examined when such data is accessible. Possible Applications and Interventions 
Each of the three insecure patterns of attachment have areas which could be focused upon in therapeutic intervention. The dismissers could benefit from a therapy focusing on understanding emotions both within themselves and within relationships, the preoccupieds need work on bolstering general views of the self, while the fearfuls could benefit from therapies aimed at building self-confidence as well as exploring the role of emotion for them within relationships. The secure group generally appeared to be coping well with environmental demands and seemed to understand emotion within the self and others quite well. No particular areas of need emerged for this group. Future research may want to examine each of the insecure groups likelihood of entering into a therapy situation. The dismissing group, for example, may deny any need for assistance since this group tends to 'dismiss' the importance of meaningful relationships.

The variation across attachment groups in the intrapersonal and interpersonal abilities of emotional intelligence also have practical implications for educational and preventive applications. Both Goleman (1995) and Bar-On (1996b) stress the importance of early intervention to promote the understanding of emotion within oneself and others. Though the styles of attachment are thought to be constructed through social interactions with important others, educational programs developed with a social-emotional competence component may help to diffuse these insecure patterns of relating.

Goleman (1995) describes several North American school districts with programs which stress areas including communicating one's feelings to others, empathizing with and understanding others emotions, and collaborating with others in devising solutions when conflicts arise. These topics are taught in conjunction with traditional grade school 
subjects such as arithmetic and language skills. Emphasizing such emotional skills as well as cognitive abilities early in a child's education may serve to prevent future difficulties by providing children with the tools to handle stressors more effectively. Properly implemented, such preventive programs may also reduce the incidence of future conduct and affective disturbances in adolescence and early adulthood.

\section{Limitations of the Study}

A significant limitation of this study is the unavailability of the validation and factor analytic studies upon which the BarOn Emotional Quotient Inventory is based. While Bar-On (1996c; 1997) states that the EQ-i has acceptable psychometric properties and that its hierarchical structure is firmly supported, these studies are not currently available within scholarly journals. In addition, at the time of the preparation of this paper, the technical manual of the BarOn EQ-i was not available because of editorial considerations. Many of the conclusions and implications discussed in this paper may need to be reevaluated once the validity and factor analytic studies are accessible.

Secondly, it is important to note that both attachment style and emotional intelligence were assessed via self-report measures, which may be problematic for several reasons. First, shared method variance of the self-report instruments may lead to response biases on the EQ-i which may differ according to style of attachment, resulting in spurious effects of the attachment patterns. Similarly, there appears to be some conceptual overlap between assessing styles of attachment and their concomitant view of self and view of others, and emotional intelligence, which relates to ratings of ones' own emotions within the self and within the context of social relationships. 
Also, self-report measures rely on one's ability to accurately report expectations and experiences within intimate relationships and within the self. This has been a frequent criticism of both attachment measures (see Bartholomew, 1994) and proposed measures of emotional intelligence (see Goleman, 1995). These researchers question an individual's ability to accurately and reliably report upon what are often assumed to be automatic and unconscious affective and thought processes. Despite these criticisms, self-report attachment measures have showed convergent validity with interviews and friend reports of attachment (Bartholomew \& Horowitz, 1991).

In regard to styles of attachment, some researchers have used self-report (e.g., Hazan \& Shaver, 1987) while others have used interview based methods of measuring styles of attachment (e.g., Main et al.,1995). Some measures attempt to assess distinct attachment categories (e.g., Hazan \& Shaver, 1987) while others utilize continuous ratings of attachment style (e.g., Collins \& Read, 1990) or have focused on dimensions thought to underlie attachment styles (e.g., Bartholomew \& Horowitz, 1991). Finally, there are measures that are based on the assumption that there are three styles of attachment while still others rely on a four-category scheme. Because of the varying perspectives inherent in the different measures of attachment, post hoc interpretations of this study were difficult since there were problems in comparing these results with findings from previous studies.

Future research needs to focus on measurement issues, particularly with respect to whether different measures of attachment are examining the same or even similar phenomena. Related to this, as the field appears to be shifting toward the four-category system of attachment, a need has been created to replicate and re-examine earlier studies 
based on the three-category scheme.

Assessing a construct such as emotional intelligence via self-report is also somewhat questionable. The EQ-i essentially asks subjects to rate their ability, for example, to empathize with the feelings with others, in order to arrive at scores for emotional intelligence. It would seem ridiculous to ask subjects to rate their abilities in mathematics through questions such as "I solve multiplication problems well" rather than through tests involving actual mathematical problems. The EQ-i appears to be a good first step in measuring emotional intelligence in that it is a well-validated self-report measure, but future research should focus on methods involving actual interpersonal problems and objective behavioral measures.

Finally, results based on primarily Caucasian students cannot be assumed to apply to other ethnic groups, age groups, or to clinical populations. Future research should focus on older, more diverse populations, and particularly on clinical populations for whom attachment phenomena may be particularly relevant in developing appropriate therapeutic interventions.

\section{Summary and Implications}

The results of this study highlight the complexity of adult attachment patterns and their relationship to the skills and abilities that encompass emotional intelligence. Each of the insecure attachment styles appears to have specific emotional deficits that could be meaningfully addressed in applied clinical settings. However, the interpretations and conclusions of this study hinge on the validity and factor analytic studies of the BarOn EQ-i. These results may need to be re-evaluated when such data is accessible. This study 
is a exploratory, preliminary step toward integrating developmental and personality research, attempting to gain a better understanding of specific strengths and areas of need in emotional capacities and how they relate to attachment patterns within a general collegiate population. Future research should include an examination of clinical populations to determine if attachment styles are related to specific forms of psychopathology as well as to more objective behavioral phenomena. Consideration should also be given to the amenability of each insecure pattern of attachment to specific forms of treatment, with a particular emphasis on outcome studies after treatment, perhaps with a focus on post-intervention outcome studies. In regards to emotional intelligence, it seems most important to focus on measurement issues, with particular emphasis on the structure and validity of the EQ-i, along with a consideration of the intersections between this construct and measures of cognitive functioning. Again researchers should include an assessment of concrete behavioral outcomes as well as paper and pencil measures. Welldesigned and controlled studies within the fields of both attachment and emotional intelligence can offer much to our understanding of personality adjustment and the etiology of affective disorders. Moreover, such research may help to lead to more effective intervention strategies for troubled individuals. 


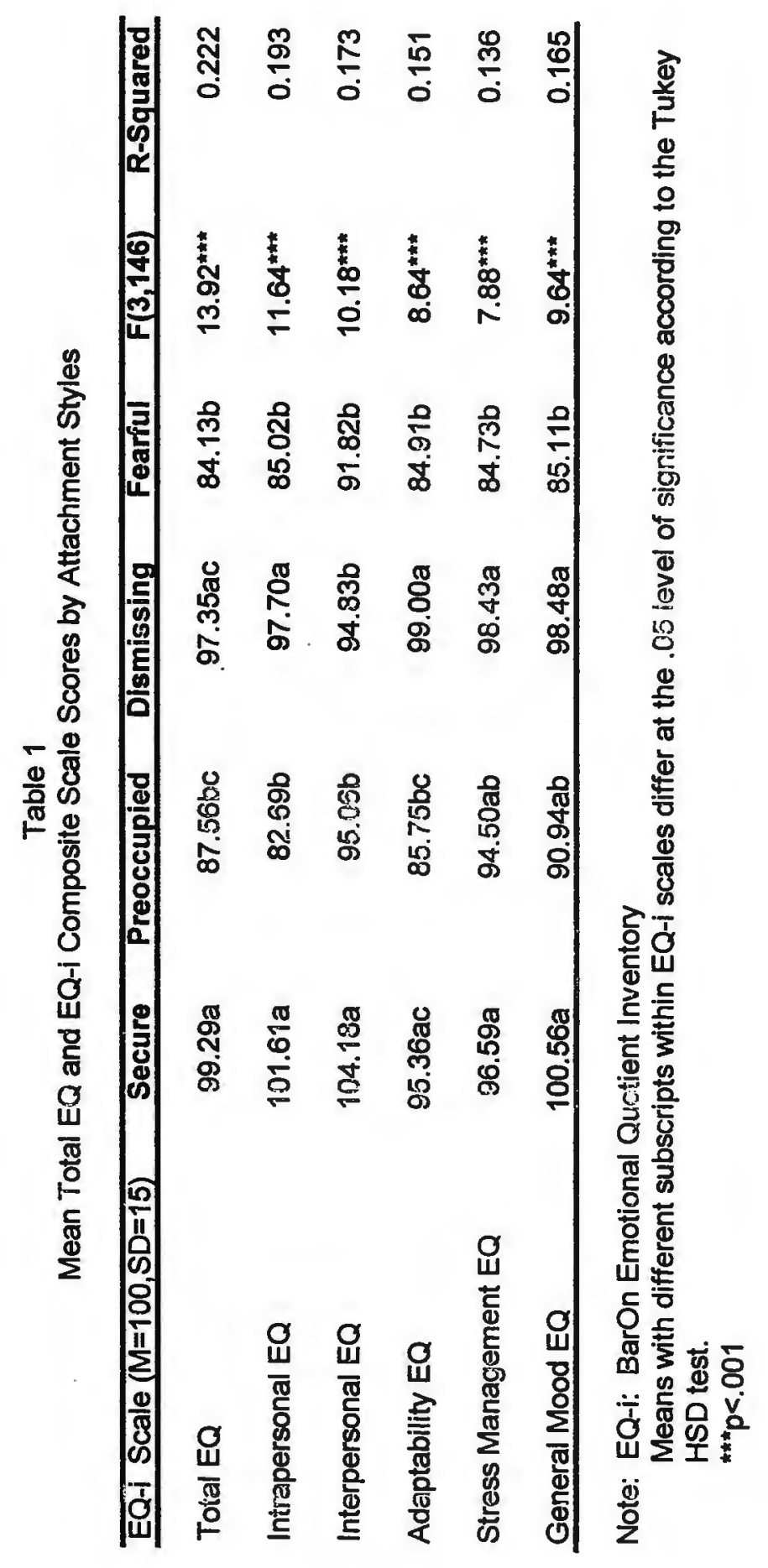




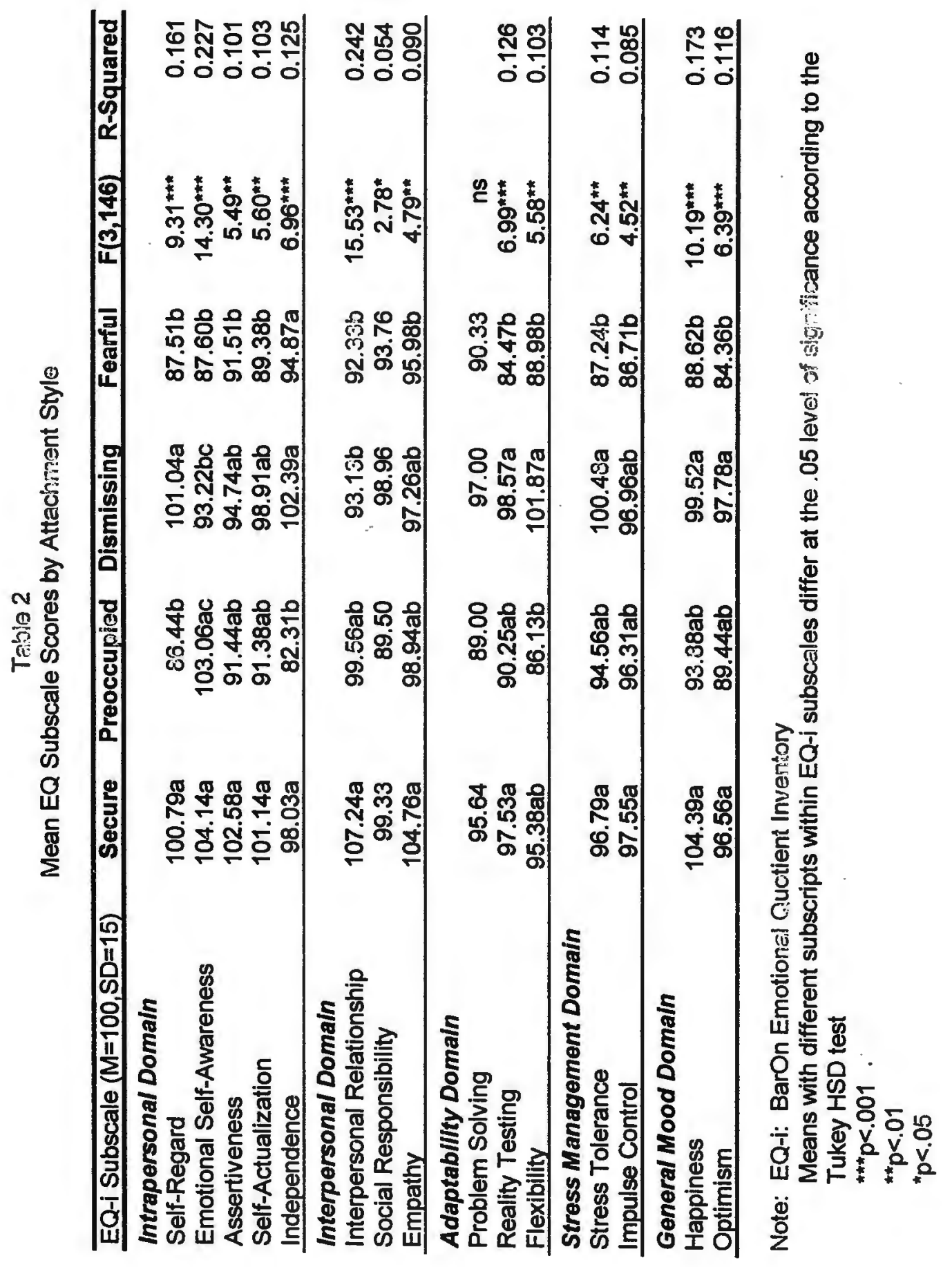




\section{Appendix A}

The following paragraphs describe ways people act or feel in emotionally close relationships. By emotionally close, we mean both romantic and non-romantic relationships that you would characterize as close (ie., caring relationships with others you trust and like or love very much). For example, you might have emotionally close relationships with your parents, romantic partners, etc. Please read each of the four descriptions below (A, B, C, and D) and indicate how much each describes the way you are or probably would be in emotionally close relationships.

\section{Circle One Number for each Description}

A. It is relatively easy for me to become emotionally close to others. I am comfortable depending on others and having others depend on me. I don't worry about being alone or having others not accept me.

$\begin{array}{ccc}\text { not at all } & \text { somewhat } & \text { very much } \\ \text { like me } & \text { like me } & \text { like me }\end{array}$

B. I want to be completely emotionally intimate with others, but I often find that others are reluctant to get as close as I would like. I am uncomfortable being without close relationships, but I sometimes worry that others don't value me as much as I value them.

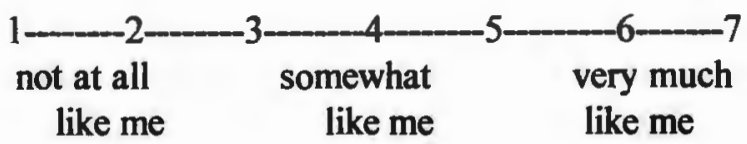

C. I am comfortable without close emotional relationships. It is very important to me to feel independent and self-sufficient, and I prefer not to depend on others or have others depend on me.

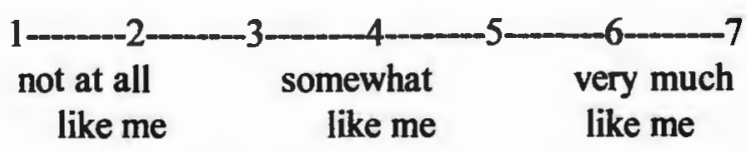

D. I am somewhat uncomfortable getting close to others. I want emotionally close relationships, but I find it difficult to trust others completely, or to depend on them. I sometimes worry that I will be hurt if I allow myself to become to close to others.

$\begin{array}{lll}\text { not at all } & \begin{array}{l}\text { somewhat } \\ \text { like me }\end{array} & \begin{array}{l}\text { very much } \\ \text { like me }\end{array}\end{array}$

Now go back and put a check on the line preceding the one description that you feel describes you best. Then go on to the next page. 
Appendix B

PLEASE COMPLETE THE FOLLOWING INFORMATION ABOUT YOURSELF (YOUR RESPONSES WILL BE KEPT IN STRICT CONFIDENTIALITY)

Age: Sex: M F (circle) Year in College: Date of Birth:

Ethnicity: White Black Hispanic Asian Other

Are you currently involved in a romantic relationship?

Yes or No (please circle)

If you answered 'yes' to the above question, please describe your satisfaction with the relationship and with your partner. If you answered 'no' to the above question, please describe your feelings about becoming romantically involved with someone in the future and/or experiences in romantic relationships in the past. Be as specific or as general as you like.

If you would be interested in taking part in future research projects related to this one, please write your name and address below.

Name:

Address:

Thank You for your Cooperation 


\section{Bibliography}

Ainsworth, M.D.S. (1967). Infancy in Uganda: Infant Care and the growth of attachment. Baltimore: John Hopkins University Press.

Ainsworth, M.D.S., Blehar, M.C., Waters, E., \& Wall, S. (1978). Patterns of attachment: A psychological study of the Strange Situation. New Jersey: Erlbaum.

Ainsworth, M.D.S. (1985). Attachments across the life-span. Bulletin of the New York Academy of Science, $61,792-812$.

Ainsworth, M.D.S. (1989). Attachments beyond infancy. American Psychologist, 44, 709-716.

Archer, D., \& Akert, R.M. (1977). Words and everything else: Verbal and nonverbal cues in social interpretation. Journal of Personality and Social Psychology, 35, 443-449.

Baldwin, M.W., Fehr, B., Keedian, E., Seidel, M., \& Thomson, D.W. (1993). An exploration of the relational schemata underlying attachment styles: Self-report and lexical decision approaches. Personality and Social Psychology Bulletin, 19(6), 746-754.

Bar-On, R. (1992). The development of a concept and test of emotional intelligence. An unpublished manuscript.

Bar-On, R. (1996a). The Emotional Quotient Inventory (EQ-i): A test of emotional intelligence. Toronto: Multi-Health Systems. 
Bar-On, R. (1996b). The era of the "EQ": Defining and assessing emotional intelligence. A paper presented at the 104th Annual APA Convention.

Bar-On, R. (1996c). The EQ-i Manual. Toronto: Multi-Health Systems.

Bar-On, R. (1997). BarOn Emotional Quotient Inventory (BarOn EQ-i): User's Manual. Toronto: Multi-Health Systems.

Bartholomew, K. (1990). Avoidance of intimacy: An attachment perspective. Journal of Social and Personal Relationships, 147-178.

Bartholomew, K., \& Horowitz, L.M. (1991). Attachment styles among young adults: A test of a four-category model. Journal of Personality and Social Psychology, 61, 226-244.

Bartholomew, K. (1994). Assessment of individual differences in adult attachment. Psychological Inquiry, 5(1), 23-27.

Benoit, D., \& Parker, K.C.H. (1994). Stability and transmission of attachment across three generations. Child Development, 65, 1444-1456.

Berman, W.H., Marcus, L., \& Berman, E.R. (1994). Attachment in marital relationships. In M.B. Sperling and W.H. Berman (Eds.), Attachment in Adults: Clinical and Developmental Perspectives, (pp. 204-231). New York: The Guilford Press. Bowlby, J. (1969). Attachment and Loss: Volume 1: Attachment. New York: Basic Books.

Bowlby, J. (1973). Attachment and Loss: Volume 2; Separation, Anxiety and Anger. New York: Basic Books. 
Bowlby, J. (1980). Attachment and Loss: Volume 3; Sadness and Depression. New York: Basic Books.

Bowlby, J. (1982). Attachment and loss: Retrospect and prospect. American Journal of Orthopsychiatry, 52, 664-678.

Bowlby, J. (1988). A secure base: Parent-child attachment and healthy human development. New York: Basic Books.

Bradford, E., \& Lyddon, W.J. (1994). Assessing adolescent and adult attachment: An update. Journal of Counseling and Development, 73, 215-219.

Brennan, K.A. \& Shaver, P.D. (1995). Dimensions of adult attachment, affect regulation, and romantic relationship functioning. Personality and Social Psychology Bulletin, 71(3), 767-783.

Bretherton, I., Ridgeway, D., \& Cassidy, J. (1990). Assessing internal working models of the attachment relationship: An attachment story completion task for 3 year olds. In M.T. Greenberg, D. Cicchetti, \& E.M. Cummings (Eds.), Attachment in the preschool years: Theory, research, and intervention, (pp. 273-308). Chicago: University of Chicago Press.

Bylsma, W., Cozzarelli, C., \& Sumer, N. (1997). Relation between adult attachment styles and global self-esteem. Basic and Applied Social Psychology, 19(1), 1-16.

Coe, M.T., Dalenberg, C.J., Aransky, K.M., \& Reto, C.S. (1995). Adult attachment style, reported childhood violence history, and types of dissociative experiences. Dissociation, 8(3), 142-154. 
Collins, N.L. \& Read, S.J. (1990). Adult attachment, working models, and relationship quality in dating couples. Journal of Personality and Social Psychology, 58(4), 644-663.

del Carmen, R. \& Huffman, L. (1996). Epilogue: Bridging the gap between research on attachment and psychopathology, Journal of Consulting and Clinical Psychology, 64(2), 291-294.

Dymond, R.F. (1949). A scale for the measurement of empathetic ability. Journal of Consulting Psychology, 13, 314-321.

Elicker, J., Egeland, M., \& Sroufe, L.A. (1992). Predicting peer competence and peer relationships from early parent-child relationships. In R. Parke \& G. Ladd (Eds.), Family-peer relations: Modes of linkage (pp. 77-106). Hillsdale, NJ: Erlbaum.

Erickson, M., Sroufe, L., \& Egeland, B. (1985). The relationship between quality of attachment and behavior problems in preschool in a high-risk sample. In I. Bretherton \& E. Waters (Eds.), Growing points of attachment theory and research. Monographs of the Society for Research in Child Development, 50(1-2, Serial No. 209), 147-166.

Feeney, J.A. \& Noller, P. (1990). Attachment style as a predictor of adult romantic relationships. Journal of Personality and Social Psychology, 58(2), 281-291.

Gardner, H. (1983). Frames of mind. New York: Basic Books.

Goffman, E. (1959). The presentation of self in everyday life. New York: Doubleday and Co.

Goleman, D. (1995). Emotional intelligence. New York: Bantom Books. 
Griffin, D., \& Bartholomew, K. (1994). Models of the self and other: Fundamental dimensions underlying measures of adult attachment. Journal of Personality and Social Psychology, 67(3), 430-445.

Grossmann, K.E., \& Grossmann, K. (1991). Attachment quality as an organizer of emotional and behavioral responses in a longitudinal perspective. In C.M. Parkes, J. Stevenson-Hinde, \& D. Marris (Eds.), Attachment across the life cycle (pp. 93-114). London: Tavistock/Routledge.

Hammond, J.R., \& Fletcher, G.. (1991). Attachment styles and relationship satisfaction in the development of close relationships. New Zealand Journal of Psychology, 20, $56-62$.

Hazan, C., \& Shaver, P.R. (1987). Romantic love conceptualized as an attachment process. Journal of Personality and Social Psychology, 52, 511-524.

Hazan, C. \& Shaver, P.R. (1994). Attachment as an organizational framework for research on close relationships. Psychological Inquiry, 5, 1-22.

Hindy, C.G., \& Schwarz, A. (1994). Anxious romantic attachment in adult relationships. In M.B. Sperling \& W.H. Berman (Eds.), Attachment in Adults: Clinical and Developmental Perspectives (pp. 179-203). New York: The Guilford Press. Horowitz, L.M. (1996). The study of interpersonal problems: A Leary legacy. Journal of Personality Assessment, 66(2), 283-300.

Jones, E.E. (1996). Introduction to the special section on attachment and psychopathology: Part 1. Journal of Consulting and Clinical Psychology, 64(1), 57. 
Kirkpatrick, L.A., \& Davis, K.E. (1994). Attachment style, gender, and relationship stability: A longitudinal analysis. Journal of Personality and Social Psychology, $66(3), 502-512$.

Kobak, R.R., \& Sceery, A. (1988). Attachment in late adolescence: Working models, affect regulation, and representation of self and others. Child Development, 59, 135-146.

Lewis, M., Feiring, C., McGuffog, C., \& Jaskir, J. (1984). Predicting psychopathology in the six-year olds from early social relations. Child Development, 55, 123-136

Londerville, S., \& Main, M. (1981). Security of attachment, compliance, and maternal training methods in the second year of life. Developmental Psychology, 17, 289-299.

Lyddon, W.J., Bradford, E., \& Nelson, J.P. (1993). Assessing adolescent and adult attachment: A review of current self-report measures. Journal of Counseling and Development, 71, 390-395.

Main, M., Kaplan, N., \& Cassidy, J. (1985). Security in infancy, childhood, and adulthood: A move to the level of representation. In I. Bretherton \& E. Waters (Eds.), Growing points of attachment theory and research. Monographs of the Society for Research in Child Development, 50 (1-2, Series No. 209), 66-104.

Main, M. (1996). Introduction to the special section on attachment and psychopathology:

2. Overview of the field of attachment. Journal of Consulting and Clinical Psychology, 64(2), 291-294. 
Mayer, J.D., \& Gaschke, Y.N. (1988). The experience and meta-experience of mood. Journal of Personality and Social Psychology, 48, 813-838.

Mayer, J., DiPaulo, M., \& Salovey, P. (1990). Perceiving affective content in ambiguous visual stimuli: A component of emotional intelligence. Journal of Personality Assessment, 54 (3/4), 772-781.

Mayer, J. \& Salovey, P. (1993). The intelligence of emotional intelligence. Intelligence, $17(4), 433-442$.

Mayer, J.D., \& Salovey, P. (1995). Emotional intelligence and the construction and regulation of feelings. Applied and Preventive Psychology, 4, 197-208.

Mehrabian, A. \& Epstein, N. (1972). A measure of emotional empathy. Journal of Personality, 40, 525-543.

Mikulincer, M., \& Florian, V., \& Tolmatz, R. (1990). Attachment styles and fear of personal death: A case study of affect regulation. Journal of Personality Social Psychology, 58, 273-280.

Mikulincer, M. \& Nachson, O. (1991). Attachment styles and patterns of self-disclosure. Journal of Personality and Social Psychology, 61(2), 321-331.

Mikulincer, M., \& Avev, I. (1991). Attachment style and the structure of romantic love. British Journal of Social Psychology, 30, 273-291.

Mikulincer, M., Florian, V., \& Weller, A. (1993). Attachment styles, coping strategies, and posttraumatic psychological distress: The impact of the Gulf War in Israel. Journal of Personality and Social Psychology, 64(5), 817-826. 
Mikulincer, M., \& Florian, V. (1995). Appraisal of and coping with a real-life stressful situation: The contribution of attachment styles. Personality and Social Psychology Bulletin, 21(4), 406-414.

Morris, W.N. (1992). A functional analysis of the role of mood in affective systems.

Review of Personality and Social Psychology, 13, 256-293.

Pistole, M.C. (1995). College students' ended love relationships: Attachment style and emotion. Journal of College Development, 36(1), 53-60.

Priel, B. \& Shamai, D. (1995). Attachment style and perceived social support: Effects on affect regulation. Personality and Individual Differences, 19(2), 235-241.

Salovey, P., \& Mayer, J. (1990). Emotional intelligence. Imagination Cognition, and Personality, 9(3), 185-211.

Schwarz, N. (1990). Feelings as information: Informational and motivational functions of affective states. In E.T. Higgins \& E.M. Sorrentino, (Eds.), Handbook of Motivation and Cognition (Vol. 2, pp. 527-561). New York: Guilford Press.

Shaver, P.R., \& Brennan, K.A. (1992). Attachment styles and the "Big Five" personality traits: Their connections with each other and with romantic relationship outcomes. Personality and Social Psychology Bulletin, 18(5), 536-545.

Shaver, P.R. \& Hazan, C. (1993). Adult romantic attachment: Theory and evidence. In D. Perlman \& W. Jones (Eds.), Advances in Personal Relationships (Vol. 4, pp. 29-70). London: Jessica Kingsley.

Simpson, J.A. (1990). Influence of attachment styles on romantic relationships. Journal of Personality and Social Psychology, 59(5), 971-980. 
Simpson, J.A., Rholes, W.S., \& Nelligan, J.S. (1992). Support seeking and support giving within couples in an anxiety provoking situation: The role of attachment styles. Journal of Personality and Social Psychology, 62(3), 434-446.

Sperling, M.B., \& Berman, W.H. (1991). An attachment classification of desperate love. Journal of Personality Assessment, 56(1), 45-55.

Sroufe, L.A., Egeland, B., \& Kreutzer, T. (1990). The rate of early experiences following developmental change: Longitudinal approaches to individual adaptation in childhood. Child Development, 61, 1363-1373.

TenHouten, W.D., Hoppe, K.D., Bogan, J.E., and Walter, D.O. (1985). Alexithymia and the split brain. Psychotherapy and Psychosomatics, 44, 113-121.

Waters, E., Wippman, J., \& Sroufe, L.A. (1979). Attachment, positive affect, and competence in the peer group: Two studies in construct valididation. Child Development, 50, 821-829.

Williams, D., \& Schill, T. (1994). Adult attachment, love styles, and self-defeating personality characteristics. Psychological Reports, 75, 31-34.

Zajonc, D.B. (1980). Feeling and thinking: Preferences need no inferences. American Psychologist, 35, 151-175.

Zuroff, D.C., \& Fitzpatrick, D.K. (1995). Depressive personality styles: Implications for adult attachment. Personality and Individual Differences, 18(2), 253-265. 